\title{
A IMPORTÂNCIA DA EDUCAÇÃO A DISTÂNCIA NA MODERNIZAÇÃO DOS PROCESSOS DE TRABALHO DO IBGE
}

\author{
Adilson Ribeiro da Silva e Ana Paula Donizetti Lins de Albuquerque \\ Escola Nacional de Ciências Estatísticas- ENCE/IBGE \\ adilson.ribeiro@ibge.gov.br
}

\begin{abstract}
O Instituto Brasileiro de Geografia e Estatística (IBGE) identificou na Educação a Distância (EaD) a possibilidade de oferecer aprendizagem contínua ao quadro de servidores. A responsabilidade foi atribuída à Escola Nacional de Ciências Estatísticas (ENCE), que recebeu em 2005 a missão de consolidar a EaD como atividade permanente, com prioridade de atendimento para a rede de 583 agências, em todo o País. Nos Censos 2007 (Contagem da População e Censo Agropecuário) foram desenvolvidos os primeiros projetos, capacitando 1922 técnicos. Em 2008 foi criada a Escola Virtual IBGE, que adotou o modelo de design instrucional clássico, por meio do qual se articulam a gestão de processos e recursos pedagógicos e tecnológicos, estruturados para facilitar a aprendizagem. Por intermédio da Escola Virtual IBGE alcançou-se o total de 28.524 concluintes, em treinamentos de curta duração. A EaD representa um passo estratégico para reforçar o processo de transformação do IBGE em organização de aprendizagem.
\end{abstract}

\section{INTRODUÇÃO}

O quadro de globalização conhecido como Era da Informação, Sociedade da Informação ou Era do Conhecimento trouxe mudanças que alteraram profundamente as dimensões econômicas, políticas e sociais da condição humana. Em grande parte resultado dos avanços tecnológicos, o fato é que na sociedade globalizada a informação e o conhecimento tornaram-se ativos estratégicos. As organizações não podem ignorar esse cenário de transformações, que acontecem em ritmo cada vez mais acelerado. Uma vez que se tornou difícil imaginar a vida contemporânea sem a presença das Tecnologias de Informação e Comunicação - TIC, não é de se admirar o impacto causado pela incorporação dessas tecnologias no espaço do ensino e da aprendizagem, bem como no âmbito organizacional. Para as organizações, a internalização de novas práticas de gestão de processos de produção e de pessoas relaciona-se principalmente à necessidade de garantir sua vantagem competitiva, como fator de sobrevivência. Os sistemas educacionais também se viram impelidos às exigências geradas por esse novo contexto, por sua função social de preparar as pessoas para a vida e o trabalho. Em outro segmento do processo educativo, constituído pelos sistemas de educação corporativa, a mudança de paradigma fez com que esses sistemas assumissem um papel estratégico dentro das organizações, levando à superação do modelo de centro de treinamento tradicional. Essencial no novo modelo é o planejamento estratégico das ações educacionais alinhado às estratégias da organização.

As instituições públicas, por sua vez, devem se alinhar às políticas e diretrizes de governo. No Brasil, o Decreto 5.707, de 2006, instituiu a Política Nacional de Desenvolvimento de Pessoal, cujas ferramentas são os planos anuais de capacitação, os relatórios de execução e os sistemas de gestão por competência. O IBGE conta com um plano anual de treinamento, por meio do qual viabiliza a formação continuada de seus servidores. Para atender às crescentes demandas por capacitação, considerando-se a necessidade de disponibilizar conhecimento de forma ampla e uniforme, inclusive por se tratar de uma Instituição de grande capilaridade, e ainda por avaliar a importância estratégica para os processos de contínua modernização organizacional, o IBGE decidiu, em 2005, instituir de forma sistemática a Educação a Distância - EaD, missão atribuída à Escola Nacional de Ciências Estatísticas - ENCE.

\section{ESTRATÉGIAS DE IMPLANTAÇÃO}

A EaD no IBGE deveria ser consolidada como atividade permanente, com prioridade de atendimento para as Unidades Estaduais e a rede de 583 agências, em todo o território nacional. O início das atividades ocorreu no âmbito de realização dos Censos 2007, quando o IBGE realizou três grandes projetos: a Contagem da População, o Censo Agropecuário e o Cadastro Nacional de Endereços para Fins Estatísticos. Além disso, houve a mudança de paradigma com a utilização de Personal Digital Assistant (PDA).

In: M.A. Sorto (Ed.), Advances in statistics education: developments, experiences and assessments. Proceedings of the Satellite conference of the International Association for Statistical Education (IASE), July 2015, Rio de Janeiro, Brazil. 
Para a modalidade a distância, nos Censos 2007, foi criado um Grupo de Tutores, com o processo interno de recrutamento, seleção e capacitação conduzido pela ENCE. Foram desenvolvidos três cursos de conteúdo operacional, com a capacitação de 1922 técnicos.

A Unidade de Gestão do Projeto de Cooperação Comissão Europeia - Mercosul aprovou a experiência do IBGE no treinamento a distância dos Censos 2007 como base para a condução de ação sobre o tema, no âmbito do projeto.

Em 2008 foi criada a Escola Virtual IBGE - EVI, tendo por premissa essencial a criação de espaços de inovação voltados para o aprendizado organizacional. Segundo Schuelter (2010), "a $\mathrm{EaD}$ contribuiu fundamentalmente para a transformação dos métodos de ensino-aprendizagem e para a organização dos processos pedagógicos"(p.31). A base da concepção da Escola Virtual IBGE considerou duas premissas estruturantes, com as quais se procura articular Educação e Gestão: a primeira reconhece a abordagem sistêmica como essencial para a compreensão e prática da educação a distância (Moore, 2011, citado em Albuquerque, 2012); a segunda tem suas fontes no universo da Gestão, destacando a importância para as organizações de se transformarem em organizações de aprendizagem. A aplicação associada das duas premissas aproxima Educação e Gestão, uma vez que a visão sistêmica exige atuação integrada, de modo que alinhe todos os subprocessos típicos de sistemas de $\mathrm{EaD}$ como fator não só de "funcionamento do sistema, mas também de sua qualidade, eficiência e eficácia" (Albuquerque, 2012, p.14), ao passo que o uso intensivo, intencional e estratégico do conhecimento, por parte das organizações, requisita para o campo da Gestão saberes e sensibilidades epistêmicas próprias da Educação.

O IBGE adotou um modelo de design instrucional amplamente utilizado: o ISD (Instructional System Design), que prevê um sequenciamento para as ações educacionais (Análise, Design, Desenvolvimento, Implementação e Avaliação). Segundo Filatro (2008), design instrucional é "o processo (conjunto de atividades) de identificar um problema (uma necessidade) de aprendizagem e desenhar, implementar e avaliar uma solução para esse problema"(p.3). Esse modelo é, geralmente, adaptado pelas organizações, e com o IBGE não foi diferente. Em função de ter constituído uma equipe reduzida frente às necessidades de trabalho, o macroprocesso de design instrucional encampou, para além das responsabilidades metodológicas e operacionais, diferentes funções organizadas distintamente em outros esquemas de trabalho. Exemplos disso são: atividades de coordenação pedagógica e coordenação de tutoria.

A criação de equipes multidisciplinares pode ser apresentada entre os fatores críticos de sucesso para os sistemas de EaD. No projeto institucional de desenho da Escola Virtual IBGE, o atendimento a essa necessidade foi associado à estratégia de destacar o processo de design instrucional como o diferencial de qualidade, além de concebê-lo como atividade essencial da qual todos, em graus diferenciados, fazem parte.

A escolha institucional para a $\mathrm{EaD}$ recaiu no formato on-line, utilizando um ambiente virtual de aprendizagem (AVA), que, segundo Behar \& Meirelles (2006, citado em Behar, 2009), "é um espaço na internet formado pelos sujeitos e suas interações e formas de comunicação que se estabelecem por meio de uma plataforma, tendo como foco principal a aprendizagem"(p.29). Nesse espaço virtual, pensado para ser a expressão principal da Escola Virtual IBGE, mas não a única, alunos, supervisores de trabalho, coordenadores de áreas técnicas, tutores, monitores e, eventualmente, visitantes, acessam os recursos disponíveis, para realizarem algo essencial à educação: interação entre os participantes do processo.

\section{PROGRAMA DE CERTIFICAÇÃO PARA O CENSO DEMOGRÁFICIO 2010}

O Programa de Certificação para o Censo 2010 foi instituído com o objetivo de fornecer aos servidores potencialmente envolvidos com a atividade censitária um conjunto de conhecimentos, independentemente de sua aplicação instrumental. Ou seja, foi estruturado para ser um programa abrangente de capacitação, precedendo as capacitações operacionais específicas que são requeridas numa operação de trabalho desse tipo. Por isso, o programa, formado por nove conteúdos programáticos distintos, incluía cursos como os de Ética, Técnicas de Didática e Pedagogia e Fundamentos de Gestão, a par de outros como Introdução à Demografia e Introdução ao Geoprocessamento.

Além desse caráter transversal, o programa teve por objetivo secundário apresentar à Instituição uma experiência preliminar com a noção de trilhas de aprendizagem, que, segundo 
Freitas (2002, citado em Freitas \& Brandão, 2006) são "caminhos alternativos e flexíveis para promover o desenvolvimento pessoal e profissional"(p.102) de um indivíduo. No Programa de Certificação para o Censo 2010, a cada aluno era permitida a opção de cursar o programa completo, que incluía prova presencial ao final, ou selecionar os cursos de seu interesse, isoladamente. Também era possível cancelar a inscrição já realizada em alguns cursos, caso optasse por outros, estando livre, portanto, para escolher o seu percurso. Cabe ressaltar o papel que tiveram as Unidades Estaduais do IBGE na aplicação da prova presencial do programa, organizada localmente, sob coordenação da ENCE.

\section{CONTEXTO ATUAL}

A Escola Virtual IBGE trabalha atualmente em duas vertentes: nas capacitações transversais e, de modo mais forte, nos treinamentos de pesquisas. A presença maior nos treinamentos voltados para as pesquisas se deve a fatores tais como: a) mudanças no desenho de certas pesquisas, especialmente a PNAD - Pesquisa Nacional por Amostra de Domicílios, que, ao passar de uma periodicidade anual para um processo de coleta contínua, exigiu a reformulação dos métodos de treinamento, antes realizados presencialmente, todos os anos, abrangendo semanas inteiras de instrução; e b) cenários de restrições orçamentárias, impostas por decisões governamentais, com impacto direto no financiamento de diárias e passagens para realização de programas presenciais de instrução extensos.

Os cursos, que são sempre objeto de projeto específico visando à proposição da solução educacional mais adequada, no contexto apresentado, são desenhados para entrega aos alunos no formato autoinstrucional ou com tutoria. Desenvolver os projetos de cada curso envolve consultoria pedagógica e estratégias concernentes ao desenvolvimento dos conteúdos, à comunicação, à mediação e à gestão.

O plano de trabalho da EVI, no que diz respeito ao treinamento de pesquisas, tem incluído projetos com as áreas econômica (Treinamento das Pesquisas Econômicas - TPE), de Geociências (Base Territorial), com o Cadastro de Endereços para Fins Estatísticos (Atualização do Setor), sociodemográfica (Pesquisa Nacional de Saúde) e de pecuária (Pesquisas Trimestrais da Pecuária).

Entre os projetos transversais, destaque para os cursos de Relacionamento com a Imprensa, Identidade cultural e alinhamento estratégico e Contabilidade aplicada às pesquisas econômicas (todos com tutoria).

Nos projetos de $\mathrm{EaD}$, a tendência é a de que cresçam em número e qualidade as ações educacionais que privilegiem os processos de aprendizagem colaborativa. $\mathrm{O}$ ambiente virtual de aprendizagem utilizado pelo IBGE possui as funcionalidades e recursos necessários para isso. O Treinamento das Pesquisas Econômicas, já com duas edições (2014 e 2015), foi concebido para envolver, em sua estruturação, tanto as áreas técnicas centralizadas quanto as supervisões técnicas descentralizadas nos estados da federação. A estratégia definida para o desenvolvimento do treinamento baseou-se numa estrutura de fóruns, sendo importante frisar a realização prévia de videoconferências, das quais participaram as áreas proponentes e a ENCE.

Depois da experiência com esse treinamento, seguiu-se a criação do Fórum Nacional para a Base Territorial, do qual podem resultar revisões em processos de trabalho e no formato das capacitações, e o Projeto Código, que é uma experiência de criação coletiva do código de boas práticas no atendimento aos usuários de informações do IBGE.

\section{CONCLUSÃO}

No cenário de mudanças permanentes, profundas e de tão largo alcance que presenciamos no mundo atualmente, pessoas, organizações e governos se esforçam tanto para garantir sua permanência quanto para ampliar, também continuamente, o estoque de competências que lhes permitam responder adequadamente aos desafios e, mais do que isso, crescer.

Apesar de variarem nas missões, perfis organizacionais e estilos de atuação, governos, instituições públicas e agentes do mundo privado compartilham o interesse na inovação e na aprendizagem contínua. A Escola Virtual IBGE nasceu como alternativa para a construção de novos espaços para o aprendizado organizacional, promovendo um processo contínuo de aprendizagem em todos os níveis funcionais, processo esse imprescindível para que as organizações aprendam a criar e inovar no contexto atual de aceleradas mudanças. 
A EaD no IBGE, por intermédio da Escola Virtual IBGE, contribuiu para aproximar e integrar as diversas unidades organizacionais, especialmente as mais dispersas pelo território nacional, facilitando a disseminação e oferta de conhecimento, de forma ampla e uniforme. As ações de educação a distância têm propiciado a exposição democrática dos temas e ampliado as possibilidades de interação, análise e crítica. Tal processo, por sua vez, contribui para a melhoria das formas de trabalho e para a própria construção do conhecimento institucional.

A modernização dos processos de trabalho constitui um desafio permanente, e, assim como estão mudando o mundo, os ambientes de trabalho e as formas de interação entre as pessoas, igualmente as estratégias de produção e revisão de métodos de trabalho precisam mudar, bem como a natureza e o tipo de envolvimento de pessoas.

Essas novas estratégias e formas de construção do conhecimento podem representar, associadas a outras iniciativas institucionais, relevante papel para a modernização dos processos de trabalho do IBGE.

\section{REFERÊNCIAS}

Albuquerque, A. P. L. (2012). O processo de Design Instrucional na Escola Virtual IBGE. Monografia de Especialização, Universidade Federal do Rio de Janeiro, Rio de Janeiro, Brasil.

Behar, P. A. (2009). Modelos pedagógicos em educação a distância. Porto Alegre, Brasil: Artmed. Filatro, A. (2008). Design instrucional na prática. São Paulo, Brasil: Pearson Education do Brasil.

Freitas, I. A., \& Brandão, H. P. (2006). Trilhas de aprendizagem como estratégia de TD\&E. In Jairo E. Borges-Andrade, Gardênia da Silva Abbad, \& Luciana Mourão, Treinamento, desenvolvimento e educação em organizações e trabalho: fundamentos para a gestão de pessoas,(1 ed., pp. 97-113). Porto Alegre, Brasil: Artmed.

Schuelter, G. (2010). Modelo de educação a distância empregando ferramentas e técnicas de gestão do conhecimento. Tese de Doutorado, Universidade Federal de Santa Catarina, Florianópolis, Santa Catarina, Brasil. 